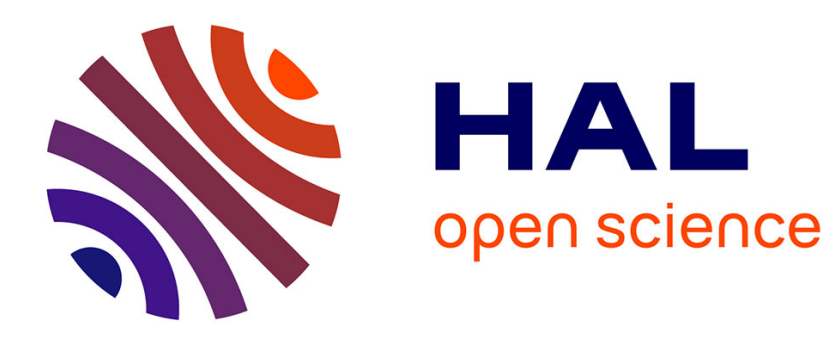

\title{
Investigations of food colloids by NMR and MRI
}

F. Mariette

\section{To cite this version:}

F. Mariette. Investigations of food colloids by NMR and MRI. Current Opinion in Colloid \& Interface Science, 2009, 14 (3), p. 203 - p. 211. 10.1016/j.cocis.2008.10.006 . hal-00455334

\section{HAL Id: hal-00455334 https://hal.science/hal-00455334}

Submitted on 10 Feb 2010

HAL is a multi-disciplinary open access archive for the deposit and dissemination of scientific research documents, whether they are published or not. The documents may come from teaching and research institutions in France or abroad, or from public or private research centers.
L'archive ouverte pluridisciplinaire HAL, est destinée au dépôt et à la diffusion de documents scientifiques de niveau recherche, publiés ou non, émanant des établissements d'enseignement et de recherche français ou étrangers, des laboratoires publics ou privés. 
Author-produced version of the article published in Current Opinion in Colloid \& Interface Science, 14 (3), $203-211$ (June 2009) Original publication available at www.sciencedirect.com - doi:10.106/j.cocis.2008.10.006

\title{
Investigations of food colloids by NMR and MRI
}

\author{
F. Mariette ${ }^{1,2}$ \\ ${ }^{1}$ Cemagref, UR TERE, 17 avenue de Cucillé, CS 64427, 35044 Rennes Cedex, France \\ francois.mariette@cemagref.fr \\ ${ }^{2}$ Université européenne de Bretagne, France
}

CURRENT OPINION IN COLLOID \& INTERFACE SCIENCE 2009 Volume: 14 Issue:

3 Pages: 203-211 


\begin{abstract}
Since the publication of the ISO method for measurement of solid fat content using NMR relaxation at low field, the application of this technique to the characterisation of food composition and food structure on several length scales has expanded considerably. Improvements in the electronic and computational specifications of NMR spectrometers and the use of more sophisticated signal processing methods have led to several new applications, and NMR, previously recognized as a powerful technique to provide information regarding composition, is now widely used for microstructural investigations. Moreover, MRI applications have in recent years been extended from the medical field to food science and this has opened up new opportunities for the understanding of food. We examine here recent developments in these techniques, including NMR relaxation, multidimensional NMR relaxation, diffusion NMR and MRI.
\end{abstract}

Keyword: magnetic resonance imaging, NMR, relaxation, diffusion, food process, gel, emulsion 


\section{Introduction}

The use of low field NMR spectrometers in the food industry began in the 70's with the commercial availability of the first benchtop NMR systems. Several applications were developed during the following years, but they were limited to the determination of water and fat content and measurement of the solid fat index. Surprisingly, the number of application did not increase much during the following twenty years. In 1992, the first International Conference on Applications of Magnetic Resonance in Food Science was organised, and since that time, with the improvements in benchtop NMR characteristics, new applications have been proposed. One of the most well-known is droplet size measurement. Moreover, the use of NMR relaxation time was proposed, not only for determination of water and fat content, but also for the investigation of food structure. Simultaneously, the use of magnetic resonance imaging techniques, in which the contrast in the image is governed by the NMR relaxation time, has emerged. MRI now is a powerful technique to monitor the composition and structural changes in foods during processing. This review focuses on the recent applications of low field NMR and MRI in food colloids and deals with recent advances such as multidimensional NMR relaxation and NMR diffusometry.

\section{Solid and liquid-like relaxation}

Most of the NMR relaxation studies on food colloids are performed with low magnetic field spectrometers typically operating at frequencies less than $25 \mathrm{Mhz}$. Since the introduction of the benchtop low magnetic field NMR equipment in the 70s, the electronic and computational specifications have improved dramatically. Short, powerful excitation pulses now permit sampling of the relaxation decay curve from $11 \mu \mathrm{s}$ up to several seconds. The number of data points available (several hundred for Free Induction Decay (FID) and several thousand for the Carr Purcell Meiboon Gill sequence (CPMG)) and the fast sampling rate (20 Mhz) are used for the simultaneous acquisition of the solid and liquid-like relaxation. Moreover, the use of continuous inverse Laplace transform methods has improved the understanding of relaxation behaviour in complex food products.

For $\mathrm{T}_{2}$ relaxation, the signal is therefore directly fitted as a sum of Gaussian functions for the solid part and the sum of exponential functions for the liquid part:

$$
Y(t)=\sum S_{i} \exp -\left(\frac{t}{T_{2}}\right)^{2}+\sum L_{i} \exp \left(-\frac{t}{T_{2}}\right)
$$




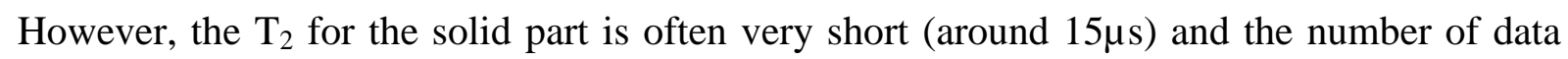
available for the fitting is to small to allow multi-Gaussian fitting because of the limitation of the sampling rate of the acquisition board, so the solid part is mainly described by a single Gaussian function.

For a specific system with a highly structured solid phase such as lipid crystals in $\beta$ polymorphic form, eq 1 becomes:

$$
Y(t)=S \exp \left(-\frac{1}{2} a^{2} t^{2}\right) \frac{\sin b t}{b t}+\sum L_{i} \exp \left(-\frac{t}{T_{2}}\right)
$$

with the second moment $\mathrm{M}_{2}$ calculated from the fitting parameters $\mathrm{a}$ and $\mathrm{b}$ with the following equation:

$$
M_{2}=a^{2}+\frac{1}{3} b^{2}
$$

According to the chemical composition of the product, the signal for the Gaussian relaxation component can be attributed to non-exchangeable protons from solid fat, ice, protein and polysaccharides, whereas, the relaxation component from the liquid phase is generally attributed to protons from liquid water and liquid fat, and from exchangeable protons from biopolymers (proteins, carbohydrates or polysaccharides). The simultaneous acquisition of solid and liquid-like relaxation has been extensively used to improve significantly the accuracy of standard NMR applications such as solid fat content, and also to carry out quantitative analysis of NMR signals from complex products such as ice cream, cake, cheese, etc., leading to new NMR applications.

\subsection{Solid and liquid fat relaxation}

Determination of solid fat content is one of the most popular applications of NMR in the food industry. Nevertheless, this international reference method is based on very crude acquisition and data processing requiring the acquisition of a pair of data points (one at $11 \mu \mathrm{s}$, which corresponds to both the solid and liquid part, and one at $70 \mu \mathrm{s}$, which corresponds to the liquid part only). Following the work of Van Duynhoven et al. [1], Trezza et al. [2] recently, demonstrated that greater accuracy in the measurement of the solid fat content could be achieved from combined FID and CPMG acquisition and when the signal is analysed with semi-empirical mathematical functions for solid, semi-solid and liquid components. An extension of this method has also been proposed in order to adapt the method to non- 
anhydrous fat products such as emulsions [3]. Indeed, in emulsions the contribution of non-fat solid-like protons such as non-echangeable protein protons to the solid phase has to be taken into account. Moreover, this method (based on the fitting of both the FID and CPMG signal) which takes into account the relaxation time and the signal intensity can be used to assess the polymorphic composition of lipids. The free induction decay of the $\alpha$ polymorph was described by a monotonously decaying Gaussian function such as eq. 1 , while for the $\beta$ and $\beta$ ' polymorph an 'Abragam sinc' function was added (eq. 2). The results demonstrated that the NMR method was potentially the first technique to provide simultaneously the amount of the solid and liquid phase and the polymorphic state of the lipid. Parallel to the development of this $\mathrm{T}_{2}$-based approach, an investigation into the behaviour of the $\mathrm{T}_{1}$ from the crystallised fat phase was carried out [4]. From an extended investigation of the effects of temperature and triacyglycerol chain lengths on the $\mathrm{T}_{1}$ and the second moment $\mathrm{M}_{2}$, the authors proved the ability of NMR to determine the polymorphism of triacylglycerols regardless of temperature. For example, a ratio of 1.5 to 2 between the $\mathrm{M}_{2}$ of the $\beta$ form and the $\alpha$ form was observed whatever the triacylglycerol, while the $\mathrm{T}_{1}$ values for the $\alpha$ polymorph were 15-25 times lower than for the $\beta$ polymorph. The sensitivity of the $T_{1}$ relaxation time of the fat crystal organisation has previously been suggested in fat mixtures with added surfactant and in food emulsions. For example, wide variations in $\mathrm{T}_{1}$ were observed according to the cooling rate of milk fat [5]. A shorter $T_{1}$ was observed for a faster cooling rate, and the $T_{1}$ was reduced when surfactants were added, compared to the $T_{1}$ from the dairy fat without surfactant. In dairy emulsions, a change in $T_{1}$ relaxation time of the fat crystal was observed according to the maturation temperature of the emulsion [6]. For a maturation temperature of $4^{\circ} \mathrm{C}$ a narrow $\mathrm{T}_{1}$ distribution was obtained, whereas a bi-modal distribution was obtained for a maturation temperature of $12^{\circ} \mathrm{C}$. Changes in the $\mathrm{T}_{1}$ relaxation time of the crystallised phase of fat have been also reported in ice cream mix and ice cream [7]. The aim of the above study was to investigate the effects of the nature of fats, proteins and emulsifiers on the behaviour of the fats in the emulsion. Despite the high complexity of the composition and structure of ice cream and mixes, NMR relaxation times specific to fat protons have been extracted from the NMR signal. The results showed a decrease in the $T_{1}$ relaxation from the solid fat after emulsification according to the nature of the fat. Moreover, an effect of the nature of the emulsifiers and the protein on the relaxation time $T_{1}$ of the fat crystal was revealed. The authors suggested that the $T_{1}$ relaxation was explained by local disorder of the crystal 
arrangement and by the size of the crystal and was related to the viscosity of the ice cream mixes.

Another improvement in the NMR relaxation method for the characterization of fat crystallisation has been proposed [8,9]. Based on the Rheo-NMR method proposed by Callaghan for the measurement of a flow under shear, the authors showed that the NMR technique can be used for the in situ measurement of solid fat content under shear. A specific mini-Couette cell was developed to crystallise fat samples under shear. The cell was tested with blends of canola stearine and canola oil melted at $80^{\circ} \mathrm{C}$, and then crystallised at $40^{\circ} \mathrm{C}$ under different shear rates inside the NMR spectrometer. This system should contribute to understanding of the effects of shear flow on the solid fat content of lipid systems.

Surprisingly, the behaviour of the signal from lipids in the liquid state has had little attention. In fact, the relaxation time of a mixture of lipids is often characterised by a wide continuous distribution of relaxation times both in $\mathrm{T}_{2}$ and $\mathrm{T}_{1}[10]$ and influenced by both the length of the carbon chain, and the amount of unsaturation [11] which complicates the interpretation of relaxation times of the lipid phase. Nevertheless, the use of chemometric methods has recently been proposed for the processing of $\mathrm{T}_{2}$ relaxation decay of intact oilseeds instead of fitting methods [12]. The partial least square method was used directly on the CPMG data in order to predict the oil quality by its composition, cetane number, iodine value and kinematic viscosity. The use of NMR has therefore been proposed for the selection of high quality oils for biodiesel applications.

Lastly, the NMR solid fat method has also been extended to MRI to study lipid migration within chocolate [13-15]. In these experiments, only the liquid signal was recorded because of the limitations of echo times when using a spin echo technique. In fact, the $T_{2}$ from the solid phase ( $\mathrm{T}_{2}$ around $15 \mu \mathrm{s}$ ) is too short to detect the solid phase. This limitation has recently been overcome by the use of a 1D centric SPRITE MRI method [16]. MR images from both the solid lipid and the liquid lipid can be acquired in a chocolate sample with this method. This new strategy will be very powerful to monitor the diffusion process of lipids in confectionery products. 


\subsection{Ice relaxation}

The simultaneous acquisition of the solid and liquid-like relaxation decay signal has also been used to investigate the ice phase during freezing. For example, two components were identified in a binary sucrose solution for temperatures above $-2^{\circ} \mathrm{C}$ [17]. The solid component was attributed to the non-exchangeable sucrose protons, and the liquid component was attributed to the water protons, the exchangeable sucrose protons and a fraction of the more mobile non-exchangeable sucrose protons. Below $-2^{\circ} \mathrm{C}$, which corresponds to the freezing temperature of water, the solid component described both the non-exchangeable sucrose protons and the ice protons. From acquisition of $\mathrm{T}_{1}$ relaxation times, the authors demonstrated that the relaxation of ice protons can be distinguished from the sucrose protons. Variation in the ice $\mathrm{T}_{1}$ relaxation time according to temperature exhibited the same behaviour as pure ice, whereas, the same authors demonstrated for the first time in a more complex product such as ice cream, that the ice relaxation time was affected by the protein types added to the formulation. The $\mathrm{T}_{1}$ relaxation time of the ice was around $3600 \mathrm{~ms}$ for ice cream containing milk protein and between 1900 and $2200 \mathrm{~ms}$ for ice cream containing whey protein (Nollibel(C). The difference was explained by the occurrence of defects in the ice crystal structure. These results open up new opportunities for the use of NMR in the characterisation of the ice in frozen food, which until now has been less fully investigated than the non-frozen water phase.

\subsection{Biopolymer relaxation}

The NMR relaxation behaviour of the solid components has also been investigated for biopolymers. For example, in milk protein mixture containing different amounts of lactose, two relaxation components were identified [18]. The short component was attributed to the non-exchangeable proton for the native protein casein, and the long component to the water proton and the lactose. Bi-exponential behaviour was also reported on $\mathrm{T}_{2}$ for soy-protein isolate films. The short relaxation component with a solid-like behaviour was more sensitive to variations in water activity and glycerol content. The $T_{2}$ variations were related to the plasticizing effect on the biopolymer films [19]. The same solid-like behaviour was also reported in gelatine biopolymer films [20]. In these matrices two relaxation times were found for the biopolymer, one for the non-echangeable protons and one for the exchangeable protons. However, the most fully studied system is still starch-based products. In the native state, the proton relaxation spectra of starch exhibit a complex multi-exponential behaviour 
$[21,22]$. In $\mathrm{D}_{2} 0$, the first relaxation peak at $10 \mu \mathrm{s}$ has been attributed to rigid amylopectin in the semi-crystalline lamellae, the relaxation peaks at $1 \mathrm{~ms}$ and $20 \mathrm{~ms}$ have been assigned to the mobile fraction of amylopectin in amorphous regions of the granule, and the longest relaxation time peak at $80 \mathrm{~ms}$ has been assigned to amylose. A decrease in the relative area of the semi-crystalline and the $1 \mathrm{~ms}$ amorphous amylopectin relaxation peaks was observed upon gelatinisation while an increase in the other two peaks was observed. In water, the starch protons exhibit a solid-like behaviour which becomes liquid-like after gelatinisation. NMR relaxation has therefore been extensively used to study the effects on the dynamic state of starch during processing such as the effects of storage temperature, water content and gluten content on starch retrogradation [23], and to investigate the gelatinisation process on rice starch [24]. The potential of NMR has recently been extended to the study of starch in complex systems containing fat and large amounts of sucrose such as cakes [25, 26]. For example, wide variations in the amount of gelatinised starch have been reported between the crust and the centre of madeleines [26]. The water gradient between the crust and the centre observed after cooking decreased during storage and was negligible after 15 days. Despite an increase in water content in the crust, no change in the starch relaxation time was observed for the solid-like component. However, an increase in the contribution of the solid starch component was observed in the centre and was related to the starch retrogradation. These results illustrated that careful analysis of the full NMR relaxation decay curves expands the potential of NMR, even in complex food system.

\subsection{Water relaxation: a multiscale probe of food structure}

The previous paragraphs have focused on improvements in NMR applications in analysis of the solid fraction of food colloids. However, the main NMR applications are based on the investigation of the water relaxation behaviour both from $T_{2}$ and $T_{1}$. Several studies have been undertaken to understand the mechanisms involved in the water relaxation rate. The main controversy concerns the relative importance of three mechanisms 1) the nature of the proteinassociated water that contributes to the relaxation, 2) the contribution of the biopolymer protons exchanging with the water, and 3) the effects of the cross-relaxation between spinlattice relaxation associated with water protons and biopolymer protons [27]. Using NMR CPMG $\mathrm{T}_{2}$ dispersion [28-31] and quantitative analysis of the $\mathrm{T}_{1}$ magnetic relaxation dispersion (MRD) [27, 32-36], it is now clear that the water relaxation can be explained by taking into account only two relaxation mechanisms, the protein-exchanging protons 
relaxation and the relaxation from the internal water molecule. Moreover, analysis of ${ }^{1} \mathrm{H},{ }^{2} \mathrm{H}$ and ${ }^{17} \mathrm{O}$ MRD has demonstrated that the internal molecules involved in this mechanism are only marginally less mobile than the bulk water and should not be considered as "bound", as they were for many years [33], and the number of water molecules is very small. For example, Venu et al [27] shown that a considerable difference in the MRD can be observed between a solution of pancreatic trypsin inhibitor and a mutant protein (G36S) lacking only one of the four internal water molecules. The water NMR relaxation in a biopolymer system has consequently to be interpreted as a probe of the biopolymer dynamics rather than a true measurement of water mobility.

Several applications have been proposed on the basis of the high sensitivity of the NMR water relaxation, i.e i) for measurement of water content with MRI, ii) for the investigation of changes in the food structure at a molecular level, iii) for the investigation of changes on a microscopic scale. Some aspects of these applications will be discussed and illustrated with some examples below.

\subsubsection{Water relaxation and water content}

The dependence of $T_{2}$ or $T_{1}$ on water content has been applied to determine oil and water content in fried food [37], to quantify the ice gradient in dough during freezing and thawing processes [38], to quantify water distribution during curd draining [39], and to monitor water ingress during rehydration of pasta $[40,41]$ and cereal-based products $[42,43]$, during drying of gelatine gels [44], and after cooking of pasta [45, 46]. An example of moisture loss during drying of gels is given in figures 1 and 2 [47]. The authors generated a simple calibration between solid content (expressed in ${ }^{\circ} \mathrm{Brix}$ ) and the $\mathrm{T}_{1}$ relaxation time (Figure 1) and a $\mathrm{T}_{1}$-null MRI sequence, which selectively nullifies the voxel with a specific $T_{1}$ value, and a specific solid content was used. In figure 2, the signal from regions with a specified solid content has been removed, clearly showing the concentration gradient across the sample. 


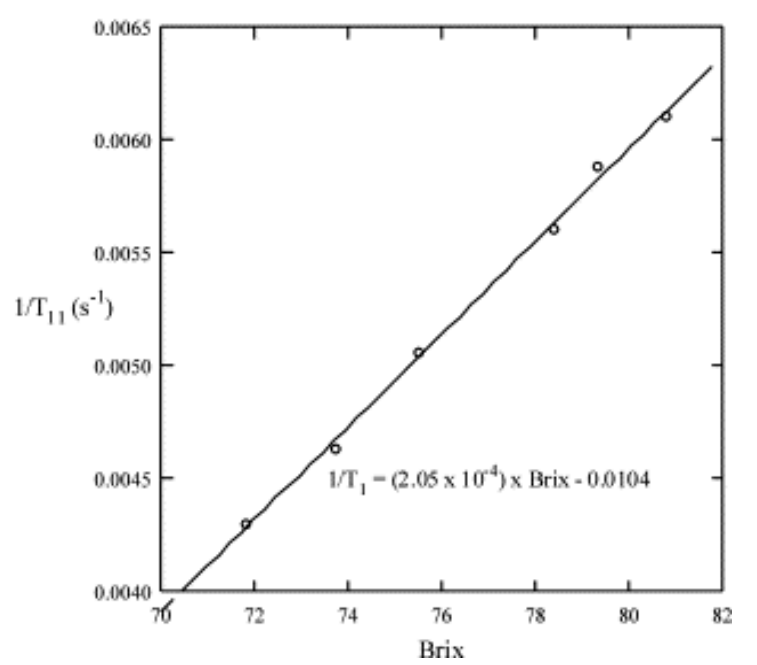

Figure 1 Calibration curve for ${ }^{\circ}$ Brix and $1 / T_{1}$ (data taken from [47]. Reprinted with permission).

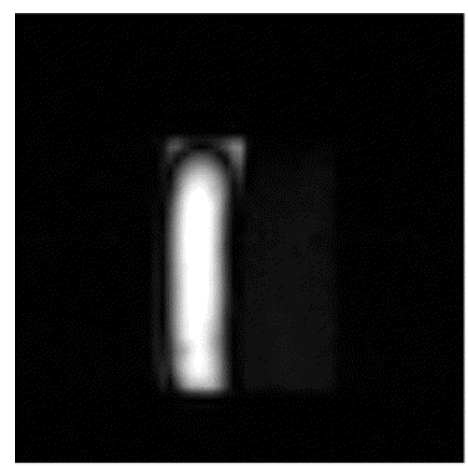

Brix $=79.4$

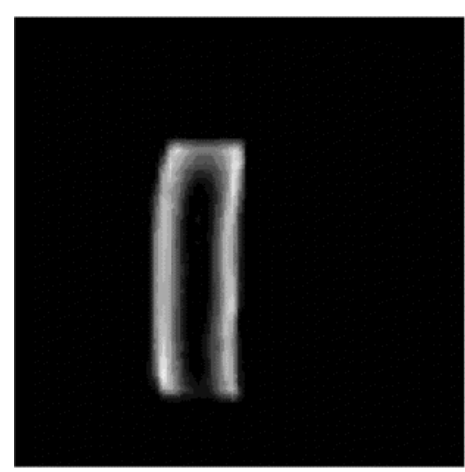

Brix $=73.9$

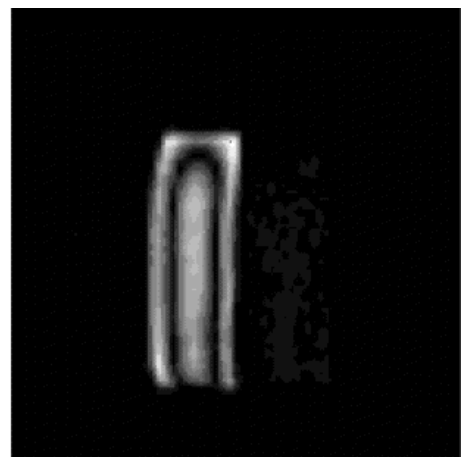

Brix $=76.7$

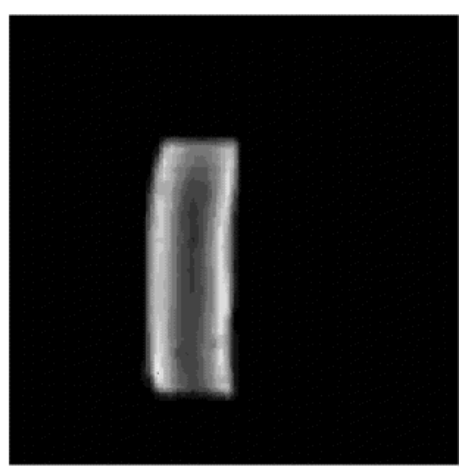

Brix $=71.2$

Figure 2 MRI transverse slice acquired with a $T_{1}$-weighted sequence of a gel during drying. The parameters of the MRI sequence were chosen in such a way that a selective nulling of the signal within the gel was observed. The dark regions therefore correspond to systems having the solid content indicated. (data taken from [47]. Reprinted with permission) 


\subsubsection{Water relaxation and molecular structure}

The dependence of relaxation on molecular structure has been extensively investigated in studies of changes in macromolecular food structure resulting from processing operations. The examples are numerous and have been extensively reviewed [48-50]. The water relaxation sensitivity to changes in the molecular dynamics of biopolymers has also been at the origin of MRI investigations into food processing operations. Consequently, if voxel intensity is $T_{2}$ value-weighted ( $T_{2}$-weighted images) information can be provided by MRI at a molecular level. However, since several processing operations induce concomitant changes in water content and molecular structure, which both affect the MRI images to a certain extent, care should be taken in the design of MRI protocols in order to provide correct interpretations of the grey level intensity of the images. It is nevertheless possible, using the appropriate MRI protocol to obtain spatial distributions on the scale defined by the voxel size (between $100 \mu \mathrm{m}$ up to several millimetres) of structural changes on a molecular scale. This property has been widely exploited for the study of cheese ripening [51], potato frying [52], freezing-thawing effects in dairy gels [39], thermal coagulation of egg white [53] and egg quality [54, 55] and gelation of carbohydrate gels [56,57], and during the evolution of the bread matrix during storage [58].

For such MRI applications, the results should be validated with specific NMR studies which provide clear descriptions of the variations in relaxation time parameters in relation to processing parameters [53]. For example, figure 3 describes the $T_{2}$ water relaxation time and the soluble protein concentrations in white egg according to temperature. Three phases can be distinguished to describe the $T_{2}$ variations. From 10 to $50^{\circ} \mathrm{C}$, the increase in $T_{2}$ is related to temperature increase through an increase in the rotational mobility of both water molecules and protein molecules. From $50^{\circ} \mathrm{C}$ to $80^{\circ} \mathrm{C}$ the $\mathrm{T}_{2}$ decreases. The decrease is explained by denaturation of the protein upon heating. Denaturation induces a decrease in rotational mobility probed by the $T_{2}$ relaxation. For this temperature range the $T_{2}$ evolution corresponds to changes in ovalbumin conformation, followed by its denaturation. Above $80^{\circ} \mathrm{C}$, only temperature affects the $T_{2}$ values. 


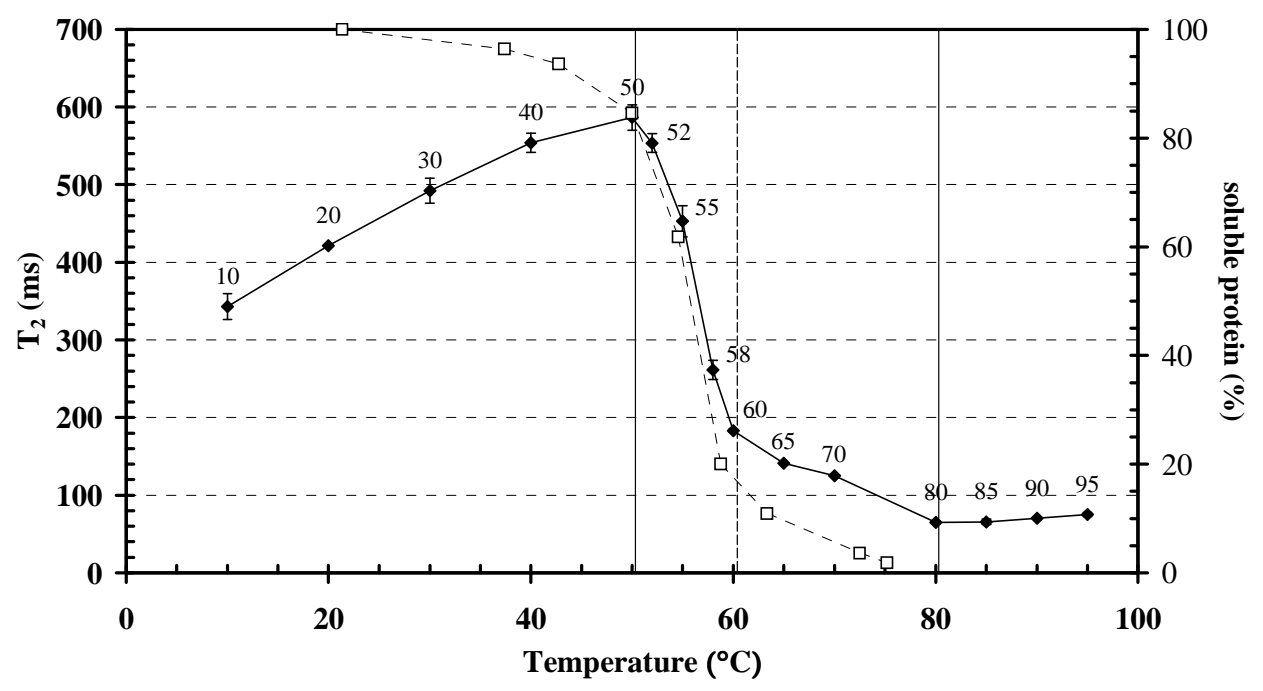

Figure 3 NMR $\mathrm{T}_{2}$ relaxation and soluble protein concentration in egg white as according to temperature (data taken from [53]. Reprinted with permission)

A complete interpretation of the MRI $\mathrm{T}_{2}$ cartography gradient observed during continuous heating of egg could therefore be proposed according to relaxation time behaviour upon changes in temperature (Figure 4). In this study the heating process was performed in one direction (from the top to the bottom), and the other walls of the container were insulated. At the beginning, uniform initial temperature $\left(17^{\circ} \mathrm{C}\right)$ and $\mathrm{T}_{2}$ values were observed. Eighteen minutes later, three areas could be distinguished, the first with $\mathrm{T}_{2}$ from 450 to $550 \mathrm{~ms}$ which corresponded to an increase in $\mathrm{T}_{2}$ because of the temperature. In this area the egg white was still liquid. The second area (from 550 to $250 \mathrm{~ms}$ ) corresponded to the area where the egg white started to coagulate, and the third (with $\mathrm{T}_{2}$ between 200 and $60 \mathrm{~ms}$ ) was attributed to the cooked egg white with a temperature above $80^{\circ} \mathrm{C}$. It should be pointed out that for a quantitative description of thermal processes, separate temperature mapping has to be performed in order to correct the $T_{2}$ value. This can be also achieved using MRI [59] 

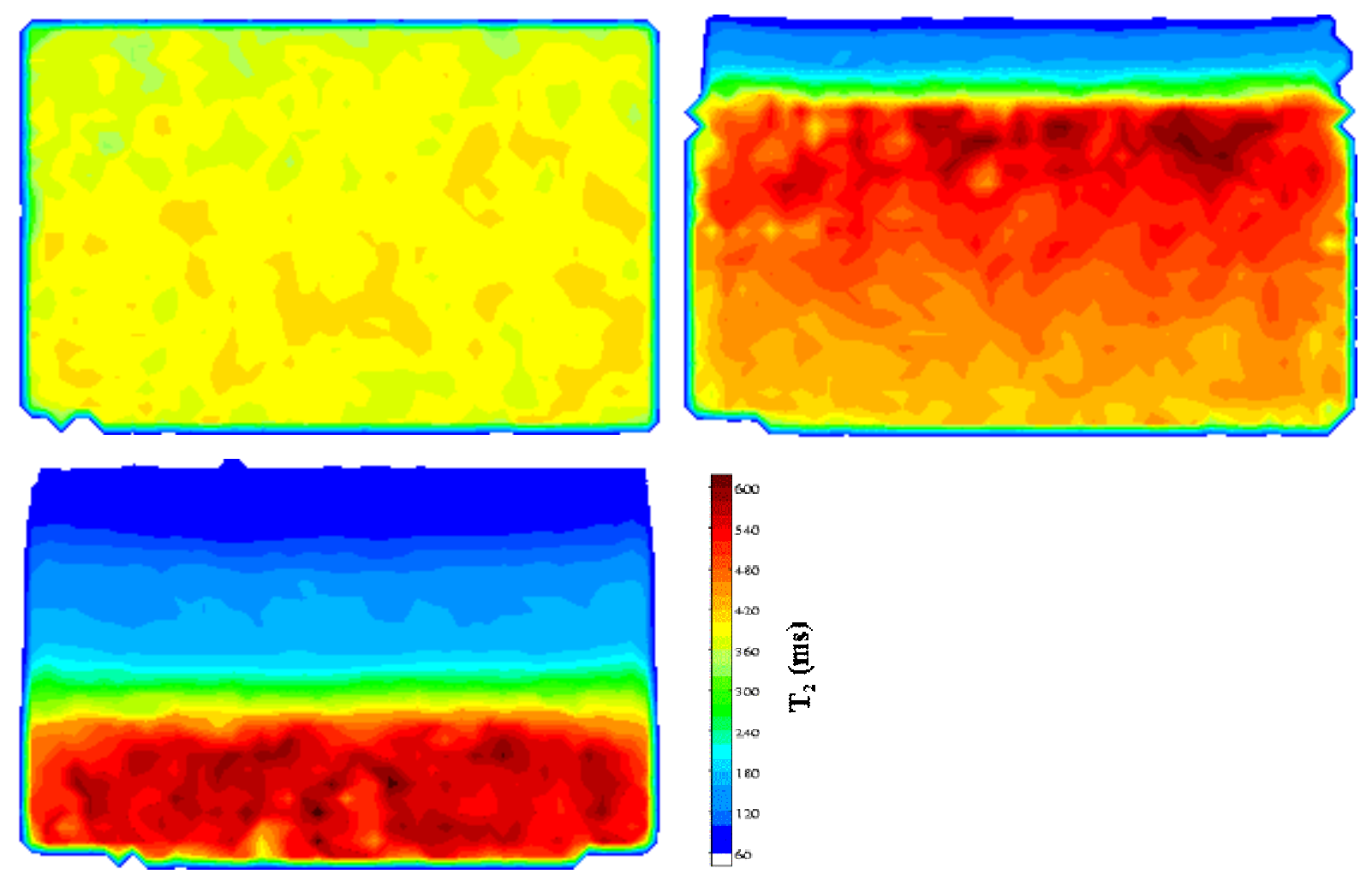

Figure 4 Transverse $T_{2}$ map of egg white during heating. All the surfaces of the beaker were insulated, and the heat exchanger was place on top of the beaker in order to limit convection flow. (data taken from [53]. Reprinted with permission)

\subsubsection{Water relaxation and microscopic structure}

The relaxation mechanism described above is only valid when the fast diffusive exchange limit is verified. In that case, because the exchange through thermal diffusion is fast, then the different water pool, the bulk and the hydration or internal water pool and the labile biopolymer are in exchange and the relaxation is the weight average of the three. Nevertheless, the $\mathrm{T}_{2}$ from water can also be complicated by the effect of translational mobility characterised by the diffusion coefficient. If we consider two different environments (1 and 2) with a size a, where the NMR characteristics of water $T_{21}$ and $T_{22}$ are different, if the diffusion coefficient rate $\left(\mathrm{D}\left(\mathrm{m}^{2} \mathrm{~s}^{-1}\right)\right)$ is fast compared to the difference in relaxation rate $\Delta \mathrm{R}_{2}$ (with $\mathrm{R}_{2}=$ $1 / \mathrm{T}_{2}$ ), water relaxation will be average and a single mono-exponential signal will be measured. The NMR signal is given by :

$$
Y(t)=A \exp \left(-\frac{t}{T_{2 o b s}}\right)
$$


with $\frac{1}{T_{2 o b s}}=\frac{P_{1}}{T_{21}}+\frac{P_{2}}{T_{22}}$

On the other hand, if the diffusion coefficient is slow compared to the relaxation rate, then the water molecule will not be exchanged and the NMR signals will be characterised by several components, each with its own relaxation time. The NMR signal then becomes:

$$
Y(t)=A_{1} \exp \left(-\frac{t}{T_{21}}\right)+A_{2} \exp \left(-\frac{t}{T_{22}}\right)
$$

In this case each signal will be an NMR signature of the two local environments. The limit between the fast and slow diffusion regimes is given by $\frac{a^{2} \Delta R_{2}}{D}<<1$.

Multi-exponential behaviour has been reported in gels and emulsions when non-uniform water distribution was observed, and therefore water relaxation behaviour has been used as a probe of the microstructure or used to quantify the water holding capacity [60-62]. For example, in dairy products, changes in water distribution were observed during syneresis of a dairy gel [39]. A bi-exponential decay relaxation curve was observed and each component was attributed to the water expelled from the gel and to the water confined in the shrunk gel, respectively. Three water relaxation components have been identified in Mozzarella cheese, one for serum water, the water accumulated in the large open channels of the protein network, one for the water inside meshes of the casein gel-like network, and one for water trapped within the casein matrix [63]. A decrease in the $\mathrm{T}_{2}$ from the serum was observed during aging, attributed to a change in the microstructure of the cheese, induced by the rearrangement of the protein network. In an imitation cheese matrix, the water relaxation was monitored at each stage of manufacture and the changes in water relaxation were described in a four-stage model of protein hydration/matrix development [64]. In rennet-derived retentates, the effects of the composition of the fat globule surface on water holding capacity have been studied [65]. Reconstituted fatty retentates were prepared from a fat-free retentate mixed with different fat-in-water emulsions stabilized with native phosphocaseinates (NPCs) or sodium caseinates. Coagulation of retentate reconstituted with native fat globules (fresh cream) and industrial fatty retentate was also investigated. The results showed that fatty products reconstituted from fresh cream and the industrial retentate presented lower water holding 
capacity than that obtained with native phosphocaseinates (NPCs) or sodium caseinate emulsions.

A multiexponential relaxation behaviour for water has consistently been reported in native starch-water systems because of slow diffusive exchange [21, 22, 24, 66-70]. Four water populations have been identified in native starch, assigned to "channel water", only observed in the B-type amylopectin crystal with a $\mathrm{T}_{2}$ around $200 \mu \mathrm{s}$, to water in the amorphous growth rings with a $\mathrm{T}_{2}$ around $1 \mathrm{~ms}$, to water in the semi-crystalline lamellae with a $\mathrm{T}_{2}$ around $8 \mathrm{~ms}$, and to the extra-granular water with a $\mathrm{T}_{2}$ longer than $30 \mathrm{~ms}$ [22]. Raising the temperature to $27^{\circ} \mathrm{C}$ causes merging of the two middle water relaxation components because of the fast diffusion of water between the amorphous growth rings and semi-crystalline lamellae. At higher temperatures, the relative intensity of this water population increases and the relaxation time decreases. This effect is explained by the swelling of the granules. Above the melting transition, the relative intensity of this component decreases considerably because of diffusion of the amylose out of the granule. Consequently, the effects of diffusive exchange between microscopic water compartments on NMR water relaxation provide a way to investigate changes during the processing of starch-based products such as non-enzymatic browning in dehrydrated potatoes [71], the effects of gluten on recrystallisation kinetics [72], the effects of gluten on gelatinisation in white bread [73], the effects of storage on cooked rice grain [74] and the effects of water content and amylopectin crystallinity pattern on polymorphic gelatinisation [75], and during rehydration of breakfast cereals [76].

The multiexponential analysis of MRI liquid relaxation has not to our knowledge been carried out on food colloids. However, examples have been proposed for in vivo medical applications showing that bi-exponential fitting of the $\mathrm{T}_{2}$ decay map improved the ability of MRI for quantitative measurements. This approach would be valuable for the characterisation of food products since most of them exhibit multiexponential relaxation behaviour.

\section{Multidimensional NMR relaxation}

The NMR applications described above are all based on the analysis of 1-dimensional conventional relaxation spectra. Although $T_{1}$-filtred $T_{2}$ or $T_{2}$-filtred acquisition has been performed for some specific applications, the data have always been processed with a 1- 
dimensional Laplace inversion [77, 78]. The advent of a fast algorithm for 2-dimensional Laplace inversion [79] has recently led to the development of "multidimensional" NMR relaxometry. These types of measurement are valuable to improve the assignment of multiexponential relaxation behaviour, and to study dynamic processes such as chemical exchange or diffusive exchange. For example, $\mathrm{T}_{2}-\mathrm{T}_{1}$ correlation and $\mathrm{D}-\mathrm{T}_{2}$ correlation experiments were performed on dairy products such as milk, yoghurt, cream and cheese [80]. For milk samples, a single peak was observed for both experiments and in that case the 2-D relaxation approach did not provide more information than a 1-D relaxation experiment. However, for the other samples a bi-modal distribution was observed for both experiments. The first peak was assigned to the water fraction and the second peak to the fat fraction. In $T_{1}-T_{2}$ correlation experiments the separation between the two relaxation components was still difficult and affected by the water content of the sample. Indeed, the results showed that the fat relaxation did not change with the chemical composition of the dairy sample, while the water relaxation associated with the water phase varied from sample to sample. Consequently, for a few samples an equal relaxation time value was observed for the two fractions thus preventing any separation of the two compounds. In contrast, the $\mathrm{D}-\mathrm{T}_{2}$ distribution functions improved separation of the water and fat features and, because of the large difference between the water diffusion and fat diffusion coefficients, this separation was independent of the chemical composition. This approach has been proposed for robust water and fat determination in dairy products. $\mathrm{T}_{1}-\mathrm{T}_{2}$ correlation spectroscopy has also been used to monitor the effects of high pressure and microwave processing on the microscopic water distribution and chain dynamics in starch-water systems and potato tissue [81]. This approach showed that high pressureinduced gels were radically different from the corresponding microwave heating-induced gels. For example, the $T_{2}-T_{1}$ correlation spectra for waxy maize starch showed only a shift for the two water peaks and for the mobile starch non-exchangeable proton after high pressure treatment. Whereas after microwave heating, the three peaks were similar to those of the untreated starch-water system, but in addition three new peaks emerged. Such methods present many opportunities for sample characterisation, but it is necessary to step back from the complexities of real food systems in order to assign the peaks to particular proton pools. As demonstrated by Marigheto et al [82], even in simple sucrose water solutions where complex $T_{1}-T_{2}$ spectra were observed, the assignment of the four peaks remained uncertain. The authors suggested that $\mathrm{T}_{1}-\mathrm{T}_{2}$ spectra can be used empirically as a "finger-print" for monitoring the complex changes associated with phase transformations. 


\section{Diffusion}

We explained above how translational mobility can modify the relaxation decay curve from mono- to multi-exponential behaviour. Nevertheless, quantification of the diffusion coefficient from relaxation time experiments is still a challenge since the physical models used require several assumptions which often cannot be verified [83]. Consequently, other NMR and MRI techniques based on the use of an external magnetic field gradient are preferred because they do not require knowledge of the mechanism involved in the relaxation behaviour. These techniques are all based on the use of well-defined linear gradient pulses which change the strength of the magnetic field probed by the molecule's protons locally. Consequently, if a molecule diffuses spatially in this magnetic field gradient, the NMR signal is reduced: the faster the diffusion rate the higher the NMR signal reduction. A detailed description of this method, called pulsed field gradient NMR (PFG-NMR), q-NMR for NMR, and diffusion weighted MRI or diffusion tensor imaging (DTI) when using an MRI scanner, is provided by Price $[83,84]$. The great advantage of MR diffusion spectroscopy and imaging is that quantitative measurement of the diffusion of water and metabolites can be performed non-invasively on a microscopic scale and in any direction of displacement. PFG-NMR is widely recognized as a powerful method to obtain microstructural information in emulsions $[85,86]\}$ and porous materials [87]. A routine PFG-NMR method has been proposed for the measurement of droplet size distribution in water/oil or oil/water emulsions [88-90]. The accuracy of the method has been widely debated for water droplet and oil droplet size determination in food emulsions such as butter, margarine and dressings [91-94]. Some extension of the method has recently been proposed for spatial determination of droplet size distribution from MRI data in emulsions [95] and to provide both real-time dispersion and spatially-resolved velocity measurements in a frozen drop of sucrose solution and emulsion [96]. However, the latter method requires the use of high field NMR spectrometers.

The PFG-NMR technique has also been used to study water mobility in different protein and polysaccharide systems. The water dependence on the protein concentration has been reported in casein and whey protein solution and gels $[97,98]$. In both systems the water diffusion was reduced with increased protein concentrations in solutions and gels. The obstruction effect of the protein was explained by taking into account two self-diffusion flows: a water flow close to the protein backbone and a water flow around the casein micelle or globular whey proteins. 
The effect of the change in network structure on the water diffusion coefficient was also investigated for casein gels. Independently of the method of preparing the gel, i.e acid or renneted gel, no difference in water diffusion was observed. However, heat treatment of the whey protein solution induced a slight reduction in the water diffusion. This was explained by a change in the accessibility of the whey protein aggregates to water. For casein, it was recognised that the overall accessibility to water was not significantly affected by the formation of a gel. The author concluded that water diffusion in protein systems follows a general trend whatever the protein system studied. The specific effects of casein and fat content on water diffusion have been outlined in a cheese model, and a general model describing the effects of water content on water self-diffusion has been proposed [65, 99]. This model includes the effects of aqueous phase composition, and the obstruction effects of casein and fat droplets on water diffusion. This model requires no structural information on the gel network since no effect of the structure has been observed, except when the water distribution inside the gel becomes heterogeneous and when the serum phase starts to release. A reduction in the water diffusion was observed in soya protein suspensions, according to the protein concentration. Moreover, the range of reductions observed was the same as that previously reported for whey protein suspension, which confirmed a general tendency to a obstruction effect induced by protein. After addition of calcium, the reduction in water selfdiffusion measured in the precipitated of soy protein isolate was greater. The author suggested that in a suspension only the hydration and hydrodynamic interactions explained the change in the self-diffusion, while in the precipitate the obstruction effect of the protein particle has to be considered and included. Nevertheless, the author did not mention whether the water content was still the same in the precipitate and in the suspension. A slight difference in water content could explain difference in the water self-diffusion between the two systems.

In contrast to protein systems where slight effects of the protein structure on the water selfdiffusion have been recorded, wide variations in water self-diffusion have been reported in starch suspensions according to the granule structure [100]. Anomalous water diffusion behaviour was found in the case of native starch. When the internal granule structure was destroyed by gelatinisation, the water diffusion conformed to simple unrestricted diffusion in 3D space. Moreover, a similar linear variation in the water self-diffusion related to the water content was observed for a fully heated wheat starch/water system, a fully heated wheat flour/water system and a fully heated rice starch/water system [101]. This suggests that the difference in microstructure after gelatinisation has little effect on the water diffusion. The 
same tendency was recently reported during retrogradation of wheat starch gel [102]. The water self-diffusion of heat-gelatinised starch and ultrahigh pressured gelatinised starch stayed constant during storage despite retrogradation. Moreover, the change in water selfdiffusion during storage of white bread crumb is mainly explained by moisture loss [103].

\section{The future}

Several studies are still in progress to improve the applications of NMR and MRI techniques to food colloids. Some of these, such as the use of multi-dimensional NMR relaxation are directly related to ways of manipulating the spin magnetisation, some involve the design of new magnet geometry such as the NMR-Mouse [104, 105], or open access systems such as the Halbach magnet [106], others involve the development of techniques to measure nonNMR parameters such as flow and rheological properties, referred to as velocimetry MRI or Rheo-NMR [107, 108], and others have proposed multi-sensor technology when NMR is associated simultaneously with other spectroscopy techniques such as NIR, impedance and ultrasound or scattering techniques [106]. Despite the development of MRI applications for food science, extrapolations to medical applications have been few, mainly because of the specificity of the different domains. However, some studies have demonstrated that in the future we will see greater levels of connection between food science and medical science and pharmaceutical applications. For example, a connection between the rehydration/dehydration processes for a food gel can be made with the monitoring of the controlled release and hydrogel volume erosion of an implant in vivo [109]. Other applications involve characterisation of food in the gastro-intestinal tract in humans and animals. Marciani et al. have used MRI to investigate the behaviour of lipid emulsions in the human stomach [110, 111]. Moreover, in order to improve the understanding of the relationship between meal viscosity and satiety, the $\mathrm{T} 2$ relaxation rate has been used to observe in vivo gelling of biopolymers in the stomach over time [112]. These recent studies demonstrate that promising new results can be expected from food MRI applications in the near future. 


\section{References and recommended readings ${ }^{* * * *}$}

[1] Van Duynhoven J, Dubourg I, Goudappel GJ, Roijers E. Determination of MG and TG phase composition by time-domain NMR. J. Am. Oil Chem. Soc. 2002; 79:383-8.

* First experimental results on the use of $\mathrm{T}_{2}$ relaxation time of the fat crystal phase for the determination of the fat crystal polymorphism

[2] Trezza E, Haiduc AM, Goudappel GJW, Van Duynhoven JPM. Rapid phasecompositional assessment of lipid-based food products by time domain NMR. Magn. Reson. Chem. 2006; 44:1023-30.

[3] Duval FP, Van Duynhoven JPM, Bot A. Practical implications of the phase-compositional assessment of lipid-based food products by time-domain NMR. J. Am. Oil Chem. Soc. 2006; 83:905-12.

[4] Adam-Berret M, Rondeau-Mouro C, Riaublanc A, Mariette F. Study of triacylglycerol polymorphs by nuclear magnetic resonance: effects of temperature and chain length on relaxation parameters. Magn. Reson. Chem. 2008; 46:550-7.

[5] Ollivon M, Relkin P, Michon C, Kalnin D, Mariette F. Crystallisation of anhydrous milk fat: Influence of polymorphism and emulsifiers. Sciences Des Aliments 2005; 25:397-411.

[6] Riaublanc A, Anton M, Mariette F, Georges C, Gravier E, Drelon N, Omari A, LealCalderon F. Impact of fat crystals on the foaming capacity and stability of whipped creams. Sciences Des Aliments 2005; 25:427-41.

[7] Lucas T, Le Ray D, Barey P, Mariette F. NMR assessment of ice cream: Effect of formulation on liquid and solid fat. Int. Dairy J. 2005; 15:1225-33.

[8] Ablett S, Darke A, Martin D. Time domain NMR studies under controlled shear conditions. In: Advances in Magnetic Resonance in Food Science. Belton PS, Hills BP, Webb GA (Editors). Cambridge: The Royal Society of Chemistry; 1999. pp. 16-23.

[9] Mazzanti G, Mudge EM, Anom EY. In situ Rheo-NMR measurements of solid fat content. J. Am. Oil Chem. Soc. 2008; 85:405-12.

[10] Chaland B, Mariette F, Marchal P, de Certaines J. H1 nuclear magnetic resonance relaxometric characterization of fat and water states in soft and hard cheese. J. Dairy Res. 2000; 67:609-18.

[11] Le Botlan DJ, Helie I. A Novel Approach to the Analysis of fats by low resolution NMR spectroscopy: application to milk and vegetable fats. Analusis 1994; 22:108-13.

[12] Prestes RA, Colnago LA, Forato LA, Vizzotto L, Novotny EH, Carrilho E. A rapid and automated low resolution NMR method to analyze oil quality in intact oilseeds. Anal. Chim. Acta 2007; 596:325-9.

[13] Walter P, Cornillon P. Lipid migration in two-phase chocolate systems investigated by NMR and DSC. Food Res. Int. 2002; 35:761-7.

[14] Choi YJ, McCarthy KL, McCarthy MJ. Oil migration in a chocolate confectionery system evaluated by magnetic resonance imaging. J. Food Sci. 2005; 70:E312-E7.

[15] Choi YJ, McCarthy KL, McCarthy MJ, Kim MH. Oil migration in chocolate. Appl. Magn. Reson. 2007; 32:205-20.

[16] Deka K, MacMillan B, Ziegler GR, Marangoni AG, Newling B, Balcom BJ. Spatial mapping of solid and liquid lipid in confectionery products using a 1D centric SPRITE MRI technique. Food Res. Int. 2006; 39:365-71.

[17] Lucas T, Mariette F, Dominiawsyk S, Le Ray D. Water, Ice and Sucrose behaviour in frozen sucrose-protein solutions as studied by 1H NMR. Food Chem. 2004; 84:77-89.

[18] Le Dean A, Mariette F, Marin M. 1H Nuclear Magnetic Resonance Relaxometry Study of Water State in Milk Protein Mixtures. J. Agric. Food Chem. 2004; 52:5449-55. 
[19] Choi SG, Kim KM, Hanna MA, Weller CL, Kerr WL. Molecular dynamics of soyprotein isolate films plasticized by water and glycerol. J. Food Sci. 2003; 68:2516-22.

[20] Kim YT, Hong YS, Kimmel RA, Rho JH, Lee CH. New approach for characterization of gelatin biopolymer films using proton behavior determined by low field H-1 NMR Spectrometry. J. Agric. Food Chem. 2007; 55:10678-84.

[21] Chatakanonda P, Chinachoti P, Sriroth K, Piyachomkwan K, Chotineeranat S, Tang HR, Hills B. The influence of time and conditions of harvest on the functional behaviour of cassava starch - a proton NMR relaxation study. Carbohydr. Polym. 2003; 53:233-40.

[22] Tang HR, Godward J, Hills B. The distribution of water in native starch granules - a multinuclear NMR study. Carbohydr. Polym. 2000; 43:375-87.

[23] Farhat IA, Blanshard JMV, Mitchell JR. The retrogradation of waxy maize starch extrudates: Effects of storage temperature and water content. Biopolymers 2000; 53:41122.

[24] Ritota M, Gianferri R, Bucci R, Brosio E. Proton NMR relaxation study of swelling and gelatinisation process in rice starch-water samples. Food Chem. 2008; 110:14-22.

[25] Assifaoui A, Champion D, Chiotelli E, Verel A. Characterization of water mobility in biscuit dough using a low-field 1H NMR technique. Carbohydr. Polym. 2006; 64:197204.

[26] Le Grand F, Cambert M, Mariette F. NMR signal analysis to characterize solid, aqueous, and lipid phases in baked cakes. J. Agric. Food Chem 2007; 55:10947-52.

[27] Venu K, Denisov VP, Halle B. Water 1H magnetic relaxation dispersion in protein solutions. A quantitative assessment of internal hydration, proton exchange, and cross relaxation. J. Am. Chem. Soc. 1997; 119:3122-34.

[28] Hills BP, Takacs SF, Belton PS. The effects of proteins on the proton NMR transverse relaxation times of water. I Native bovine serum albumine. Molec. Phys. 1989; 67:903-18.

* On the evidence of the dominant effect of the chemical exchange mechanism on the proton NMR relaxation time of water.

[29] Hills BP, Takacs SF, Belton PS. The effects of proteins on the proton NMR transverse relaxation time of water. II protein aggregation. Molec. Phys. 1989; 67:919-37.

* On the evidence of the dominant effect of the chemical exchange mechanism on the proton NMR relaxation time of water.

[30] Belton PS, Ring SG, Botham RL, Hills BP. Multinuclear NMR studies of water in solutions of simple carbohydrates. II. Oxygen-17 relaxation. Molec. Phys. 1991; 72:112334.

[31] Hills BP. Multinuclear NMR studies of water in solutions of simple carbohydrates. I proton and deuterium relaxation. Molec. Phys. 1991; 72:1099-121.

[32] Denisov VP, Halle B. Hydrogen exchange rates in proteins from water $\mathrm{H}-1$ transverse magnetic relaxation. J. Am. Chem. Soc. 2002; 124:10264-5.

[33] Halle B. Protein hydration dynamics in solution: a critical survey. Philos. Trans. R. Soc. Lond. Ser. B-Biol. Sci. 2004; 359:1207-23.

$* *$ to date the most extensive review on protein hydration

[34] Chavez FV, Halle B. Molecular basis of water proton relaxation in gels and tissue. Magn. Reson. Med. 2006; 56:73-81.

[35] Chavez FV, Hellstrand E, Halle B. Hydrogen exchange and hydration dynamics in gelatin gels. J. Phys. Chem. B 2006; 110:21551-9.

[36] Chavez FV, Persson E, Halle B. Internal water molecules and magnetic relaxation in agarose gels. J. Am. Chem. Soc. 2006; 128:4902-10.

[37] Hickey H, MacMillan B, Newling B, Ramesh M, Van Eijck P, Balcom B. Magnetic resonance relaxation measurements to determine oil and water content in fried foods. Food Res. Int. 2006; 39:612-8. 
[38] Lucas T, Grenier A, Quellec S, Le Bail A, Davenel A. MRI quantification of ice gradients in dough during freezing or thawing processes. J. Food Eng. 2005; 17:98-108.

[39] Mariette F. NMR relaxometry and MRI for food quality control: application to dairy products and processes. In: Magnetic Resonance in Food Science: Latest Developments. Webb A, Belton PS, Gill AM, Rutledge DN (Editors). Cambridge: Royal Society of Chemistry; 2003. p. 209.

[40] Hills BP, Babonneau F, Quantin VM, Gaudet F, Belton PS. Radial NMR microimaging studies of the rehydration of extruded pasta. J. Food Eng. 1996; 27:71-86.

[41] Lai HM, Hwang SC. Water status of cooked white salted noodles evaluated by MRI. Food Res. Int. 2004; 37:957-66.

[42] Ramos-Cabrer P, Van Duynhoven JPM, Timmer H, Nicolay K. Monitoring of moisture redistribution in multicomponent food systems by use of magnetic resonance imaging. $\mathrm{J}$. Agric. Food Chem. 2006; 54:672-7.

[43] Weglarz WP, Hemelaar M, van der Linden K, Franciosi N, van Dalen G, Windt C, Blonk H, van Duynhoven J, Van As H. Real-time mapping of moisture migration in cereal based food systems with A(w) contrast by means of MRI. Food Chem. 2008; 106:1366-74.

[44] Chung YL, Lai HM. Water status of two gelatin gels during storage as determined by magnetic resonance imaging. J. Food Drug Anal. 2004; 12:221-7.

[45] Xing HJ, Takhar PS, Helms G, He B. NMR imaging of continuous and intermittent drying of pasta. J. Food Eng. 2007; 78:61-8.

[46] McCarthy KL, Gonzalez JJ, McCarthy MJ. Change in moisture distribution in lasagna pasta post cooking. J. Food Sci. 2002; 67:1785-9.

[47] Ziegler GR, MacMillan B, Balcom BJ. Moisture migration in starch molding operations as observed by magnetic resonance imaging. Food Res. Int. 2003; 36:331-40.

[48] Hills B. Magnetic resonance imaging in food science. New York: A Wiley Interscience publication; 1998.

[49] Ruan RR, Chen PL. Water in foods and biological materials. A nuclear magnetic resonance approach. Lancaster: Technomic Publishing Co. Inc.; 1998.

[50] Mariette F. NMR relaxation of dairy products. In: Modern Magnetic Resonance, Part 3: Applications in Materials Science and Food Science. Webb GA (Editor) Springer; 2006. pp. 1675-9.

[51] Mariette F. NMR imaging of dairy products. In: Modern Magnetic Resonance, Part 3: Applications in Materials Science and Food Science. Webb GA (Editor) Springer; 2006. pp. 1779-84.

[52] Mariette F, Brannelec C, Vitrac O, Bohuon P. Effet du procédé de friture sur la répartition et l'état de l'eau mesurée par RMN et IRM. In: Les produits alimentaires et l'eau, Agoral 99. Nantes: Edition Tec \& Doc; 1999. pp. 411-6.

[53] Lucas T, Mariette F, Cambert M, Rodrique M. Thermal coagulation of egg white: an MRI study of the process and a tentative NMR interpretation. In: 6th international conference on applications of magnetic resonance in food science, Paris, 4-6 septembre 2002. 2002.

[54] Laghi L, Cremonini MA, Placucci G, Sykora S, Wright K, Hills B. A proton NMR relaxation study of hen egg quality. Magn. Reson. Imaging 2005; 23:501-10.

[55] Schwagele F, Poser R, Krockel L. Low resolution proton nuclear magnetic resonance spectroscopy - Application to determine the internal quality of intact eggs - physicochemical aspects. Fleischwirtschaft 2005; 85:107-9.

[56] Potter K, Balcom BJ, Carpenter TA, Hall LD. The gelation of sodium alginate with calcium ions studied by magnetic resonance imaging (MRI). Carbohydr. Res. 1994; 257:117-26. 
[57] Duce SL, Carpenter TA, Hall LD. Use of NMR imaging to map spatial distribution of structure in polysaccharide gels. Carbohydr. Res. 1990:C1-C4.

[58] Lodi A, Abduljalil AM, Vodovotz Y. Characterization of water distribution in bread during storage using magnetic resonance imaging. Magn.Reson. Imaging 2007; 25:144958.

[59] Nott KP, Hall LD. Validation and cross-comparison of MRI temperature mapping against fibre optic thermometry for microwave heating of foods. Int. J. Food Sci. Technol. 2005; 40:723-30.

[60] Haiduc AM, van Duynhoven JPM, Heussen P, Reszka AA, Reiffers-Magnani C. Multivariate modelling of the microstructural quality of food emulsions based on NMR. Food Res. Int. 2007; 40:425-34.

[61] Hinrichs R, Gotz J, Noll M, Wolfschoon A, Eibel H, Weisser H. Characterisation of the water-holding capacity of fresh cheese samples by means of low resolution nuclear magnetic resonance. Food Res. Int. 2004; 37:667-76.

[62] Hinrichs R, Gotz J, Weisser H. Water-holding capacity and structure of hydrocolloidgels, WPC-gels and yogurts characterised by means of NMR. Food Chem. 2003; 82:15560.

[63] Gianferri R, D'Aiuto V, Curini R, Delfini M, Brosio E. Proton NMR transverse relaxation measurements to study water dynamic states and age-related changes in Mozzarella di Bufala Campana cheese. 2007; 105:720-6.

[64] Noronha N, Duggan E, Ziegler GR, O'Riordan ED, O'Sullivan M. Investigation of imitation cheese matrix development using light microscopy and NMR relaxometry. Int. Dairy J. 2008; 18:641-8.

[65] Metais A, Cambert M, Riaublanc A, Mariette F. Influence of fat globule membrane composition on water holding capacity and water mobility in casein rennet gel: A nuclear magnetic resonance self-diffusion and relaxation study. Int. Dairy J. 2006; 16:344-53.

[66] Tang HR, Brun A, Hills B. A proton NMR relaxation study of the gelatinisation and acid hydrolysis of native potato starch. Carbohydr. Polym. 2001; 46:7-18.

[67] Chatakanonda P, Dickinson LC, Chinachoti P. Mobility and distribution of water in cassava and potato starches by H-1 and H-2 NMR. J. Agric. Food Chem. 2003; 51:7445-9.

[68] Choi SG, Kerr WL. Water mobility and textural properties of native and hydroxypropylated wheat starch gels. Carbohydr. Polym. 2003; 51:1-8.

[69] Thygesen LG, Blennow A, Engelsen SB. The effects of amylose and starch phosphate on starch gel retrogradation studied by low-field H-1 NMR relaxometry. Starch 2003; 55:241-9.

[70] Doona CJ, Baik MY. Molecular mobility in model dough systems studied by timedomain nuclear magnetic resonance spectroscopy. J. Cereal Sci. 2007; 45:257-62.

[71] Acevedo NC, Schebor C, Buera P. Non-enzymatic browning kinetics analysed through water-solids interactions and water mobility in dehydrated potato. Food Chem. 2008; 108:900-6.

[72] Wang X, Choi SG, Kerr WL. Effect of gluten content on recrystallisation kinetics and water mobility in wheat starch gels. J. Sci. Food Agric. 2004; 84:371-9.

[73] Wang X, Choi SG, Kerr WL. Water dynamics in white bread and starch gels as affected by water and gluten content. Lebensm.-Wiss. Technol.-Food Sci. Technol. 2004; 37:37784.

[74] Yano S, Arata K, Suzuki S, Yamazaki K, Suzuki N, Kanzaki Y. Pulse NMR study of refrigerated cooked rice and comparison with physicochemical properties. Food Sci. Technol. Res. 2004; 10:218-23.

[75] Tananuwong K, Reid DS. DSC and NMR relaxation studies of starch-water interactions during gelatinization. Carbohydr. Polym. 2004; 58:345-58. 
[76] Lucas T, Le Ray D, Mariette F. Kinetics of water absorption and solute leaching during soaking of breakfast cereals. J. Food Eng. 2007; 80:377-84.

[77] Mariette F, Lucas T. NMR signal analysis for the attribution of the components to the solid/liquid phases in presence in mixes and ice creams. J. Agric. Food Chem. 2005; 53:1317-27.

* The first quantitative analysis of the NMR $\mathrm{T}_{1}$ and $\mathrm{T}_{2}$ relaxation multi-exponential behaviour in a complex colloidal food system.

[78] Witek M, Peemoeller H, Szymonska J, Blicharska B. Investigation of starch hydration by 2D time domain NMR. Acta Phys. Pol. A 2006; 109:359-64.

[79] Song YQ, Venkataramanan L, Hurlimann MD, Flaum M, Frulla P, Straley C. T-1-T-2 correlation spectra obtained using a fast two- dimensional Laplace inversion. J. Magn. Reson. 2002; 154:261-8.

[80] Hurlimann MD, Burcaw L, Song YQ. Quantitative characterization of food products by two-dimensional D-T-2 and T-1-T-2 distribution functions in a static gradient. J. Colloid Interface Sci. 2006; 297:303-11.

[81] Hills B, Costa A, Marigheto N, Wright K. T-1-T-2 NMR correlation studies of highpressure-processed starch and potato tissue. Appl. Magn. Reson. 2005; 28:13-27.

[82] Marigheto N, Venturi L, Hibberd D, Wright KM, Ferrante G, Hills BP. Methods for peak assignment in low-resolution multidimensional NMR cross-correlation relaxometry. J. Magn. Reson. 2007; 187:327-42.

** The first tentative for a complete assignment of the peak for a multidimensional NMR cross-correlation relaxometry investigation of an aqueous sucrose system.

[83] Price WS. Pulsed field gradient nuclear magnetic resonance as a tool for studying translational diffusion: Part 1. Basic Theory. Concept. Magnetic Res. 1997; 9:299-336.

[84] Price WS. Pulsed-field gradient nuclear magnetic resonance as a tool for studying translational diffusion : Part II. Experimental aspects. Concept. Magnetic Res. 1998; 10:197-237.

[85] Johns ML, Hollingsworth KG. Characterisation of emulsion systems using NMR and MRI. Prog. Nucl. Magn. Reson. Spectrosc. 2007; 50:51-70.

[86] Colafemmina G, Palazzo G, Ceglie A, Ambrosone L, Cinelli G, Di Lorenzo V. Restricted diffusion: An effective tool to investigate food emulsions. Prog. Colloid Polym. Sci. 2002; 120:23-7.

[87] Topgaard D. Probing biological tissue microstructure with magnetic resonance diffusion techniques. Curr. Opin. Colloid Interface Sci. 2006; 11:7-12.

[88] Balinov B, Soderman O, Warnheim T. Determination of water droplet size in margarines and low-calorie spreads by nuclear magnetic resonance self-diffusion. J. Am. Oil Chem. Soc. 1994 ; 71:513-8.

[89] Mooren MMW, Gribnau MCM, Voorbach MA. Determination of droplet size distributions in emulsions by pulsed field gradient NMR. In: Characterization of Food. Gaonkar AG (Editor) Amsterdam: Elsevier; 1995. pp. 151-62.

[90] Goudappel GJW, van Duynhoven JPM, Mooren MMW. Measurement of oil droplet size distributions in food Oil/Water emulsions by time domain Pulsed Field Gradient NMR. J. Colloid Interface Sci. 2001; 239:535-42.

[91] Van Duynhoven JPM, Goudappel GJW, van Dalen G, van Bruggen PC, Blonk JCG, Eijkelenboom APAM. Scope of droplet size measurements in food emulsions by pulsed field gradient NMR at low field. Magn. Reson. Chem. 2002; 40:S51-S9.

[92] Van Dalen G. Determination of the water droplet size distribution of fat spreads using confocal scanning laser microscopy. J. Microsc.-Oxf. 2002; 208:116-33. 
[93] Van Lent K, Vanlerberghe B, Van Oostveldt P, Thas O, Van der Meeren P. Determination of water droplet size distribution in butter: Pulsed field gradient NMR in comparison with confocal scanning laser microscopy. Int. Dairy J. 2008; 18:12-22.

[94] Denkova PS, Tcholakova S, Denkov ND, Danov KD, Campbell B, Shawl C, Kim D. Evaluation of the precision of drop-size determination in oil/water emulsions by lowresolution NMR spectroscopy. Langmuir 2004; 20:11402-13.

[95] d'Avila MA, Powell RL, Phillips RJ, Shapley NC, Walton JH, Dungan SR. Magnetic resonance imaging (MRI): A technique to study flow an microstructure of concentrated emulsions. Braz. J. Chem. Eng. 2005; 22:49-60.

[96] Hindmarsh JP, Sederman AJ, Gladden LF, Wilson DI, Johns ML. Rapid measurement of dispersion and velocity in freezing drops using magnetic resonance methods. Experiments in Fluids 2005; 38:750-8.

[97] Colsenet R, Cambert M, Mariette F. NMR relaxation and water self-diffusion studies in whey protein solutions and gels. J. Agric. Food Chem. 2005; 53:6784-90.

[98] Mariette F, Topgaard D, Jonsson B, Soderman O. H-1 NMR diffusometry study of water in casein dispersions and gels. J. Agric. Food Chem. 2002; 50:4295-302.

* The first study on water diffusion in dairy system including experimental results and a physical model based on two water flows.

[99] Métais A, Cambert M, Riaublanc A, Mariette F. Effects of casein and fat content on water self-diffusion coefficients in casein systems: a pulsed field gradient nuclear magnetic resonance study. J. Agric. Food. Chem. 2004; 52:3988-95.

[100] Hills BP, Godward J, Manning CE, Biechlin JL, Wright KM. Microstructural characterization of starch systems by NMR relaxation and Q-SPACE microscopy. Magn. Reson. Imaging 1998; 16:557-64.

[101] Fukuoka M, Mihori T, Watanabe H. MRI observation and mathematical model simulation of water migration in wheat flour dough during boiling. J. Food Sci. 2000; 65:1343-8.

[102] Doona CJ, Feeherry FE, Baik MY. Water dynamics and retrogradation of ultrahigh pressurized wheat starch. J. Agric. Food Chem. 2006; 54:6719-24.

[103] Baik MY, Chinachoti P. Water self-diffusion coefficient and staling of white bread as affected by glycerol. Cereal Chem. 2003; 80:740-4.

[104] Haiduc AM, Trezza EE, van Dusschoten D, Reszka AA, van Duynhoven JPM. Noninvasive 'through-package' assessment of the microstructural quality of a model food emulsion by the NMR MOUSE. LWT-Food Sci. Technol. 2007; 40:737-43.

[105] Guthausen A, Guthausen G, Kamlowski A, Todt H, Burk W, Schmalbein D. Measurement of fat content of food with single-sided NMR. J. Am. Oil Chem. Soc. 2004; 81:727-31.

[106] Hills BP, Wright KM, Gillies DG. A low-field, low-cost Halbach magnet array for open-access NMR. J. Magn. Reson. 2005; 175:336-9.

[107] Hollingsworth KG, Johns ML. Rheo-nuclear magnetic resonance of emulsion systems. J. Rheol. 2004; 48:787-803.

[108] Callaghan PT. Rheo-NMR and velocity imaging. Curr. Opin. Colloid Interface Sci. 2006; 11:13-8.

[109] Weissleder R, Posse K, Wilkinson R, Zhou C, Bogdanov A. Quantitation of slow drugrelease from an implantable and degradable gentamicin conjugate by in-vivo magneticresonance. Antimicrob. Agents and Chemother. 1995; 39:839-45.

[110] Marciani L, Wickham M, Hills BP, Wright J, Bush D, Faulks R, Fillery-Travis A, Spiller RC, Gowland PA. Intragastric oil-in-water emulsion fat fraction measured using inversion recovery echo-planar magnetic resonance imaging. J. Food Sci. 2004; 69:E290E6. 
[111] Marciani L, Wickham MSJ, Bush D, Faulks R, Wright J, Fillery-Travis AJ, Spiller RC, Gowland PA. Magnetic resonance imaging of the behaviour of oil-in-water emulsions in the gastric lumen of man. Br. J. Nutr. 2006; 95:331-9.

[112] Hoad CL, Rayment P, Spiller RC, Marciani L, Alonso BD, Traynor C, Mela DJ, Peters HPF, Gowland PA. In vivo imaging of intragastric gelation and its effect on satiety in humans. J. Nutr. 2004; 134:2293-300.

** to date, the first in vivo investigation of gelation of polysaccharide in the stomach

* Of special interest.

*** Of oustanding interest 